\title{
Enfermedad por arañazo de gato: un nuevo planteamiento diagnóstico
}

\author{
M.T. González Martínez, C. Mosquera Villaverde, P. Heredia lama* \\ Pediatras. Servicio de Pediatría. Hospital del Bierzo. Ponferrada. León. \\ *M édico de familia. Área de Salud del Bierzo. Ponferrada. León.
}

\section{RESUMEN}

La Enfermedad por Arañazo de Gato (EAG) es una enfermedad autolimitada, relativamente benig na. Sus manifestaciones clínicas presentan una gran variabilidad existiendo una forma típica: linfoade nopatía regional subaguda, y un amplio abanico de formas atípicas con manifestaciones sistémicas.

Los estudios microbiológicos, serológicos y mole culares han demostrado que la Bartonella henselae es el agente etiológico de la EAG.

Los resultados serológicos, que deben interpre tarse con precaución y cojuntamente con la clínica y epidemiología, posibilitan un diagnóstico rápido, evitando investigaciones invasivas. Su utilización como criterio posibilita el manejo de esta enferme dad desde Atención Primaria.

Se presentan dos casos reflejando las considera ciones previas.

Palabras clave: Enfermedad por asañazo de ga to. Serología. Diagnóstico.

Cat scratch disease: a new diagnostic assessment

\section{ABSTRACT}

Cat Scratch Disease (CSD) is usually a self-limi ted illness associated with tender lymph nodes, fever, malaise, and fatigue. Lymphadenopathy usually re solves spontaneously within three to four months. Systemic manifestations of CSD are less frequent however show a wide spectrum.

Microbiological, serological and molecular stu dies have demonstrated that Bartonella henselae is the etiologic agent in most cases of CSD.

Interpretation of the results of serology should be cautious and always related to the clinical and epi demiological picture of the patient but serology pro vides rapid diagnosis, avoiding multiple and invasi ve investigations. The consideration of this technique as criteria in the diagnosis of CSD would be possible its extrahospitalary management in most cases.

Two cases sum as previous consideration are des cribed.

Key words: Cat scratch disease. Serology. Diag nosis.

\section{INTRODUCCIÓN}

La enfermedad por arañazo de gato es una enfermedad autolimitada, relativamente benigna, que puede aparecer en personas de cualquier edad pero que afecta prioritariamente a niños y adolescentes.

Sus manifestaciones clínicas presentan una gran variabilidad $^{1}$ existiendo una forma típica: linfoadenopatía regional subaguda; y un amplio abanico de formas atípicas que pueden afectar prácticamente a cualquier órgano de la economía: piel, sistema nervioso, páncreas, hígado, riñón, bazo, ojos, hueso, etc.
Aunque su etiología fue durante mucho tiempo un problema sin resolución definitiva, desde el inicio de los 90 se ha aceptado que la Bartonella henselae desempeña el papel de principal agente etiológico en esta enfermedad ${ }^{2-4}$. En la actualidad, los test serológicos para la determinación de sus anticuerpos específicos y las técnicas de detección a través de la reacción en cadena de la polimerasa han llegado a desplazar a los criterios diagnósticos tradicionales ${ }^{5,6}$, haciendo posible su detección desde Atención Primaria.

Recientemente hemos estudiado un caso de fiebre de origen desconocido y uno de adenopatía locorregional subaguda. En el primero de ellos se sospechó 
una fiebre botonosa, posteriormente las técnicas de imagen pusieron de manifiesto múltiples lesiones esplénicas y hepáticas que orientaron el diagnóstico. En ambos casos se utilizó como complemento diagnóstico la determinación de anticuerpos frente a Bar tonella henselae, no precisando técnicas invasivas.

\section{OBSERVACIONES CLÍNICAS}

\section{Caso 1}

Se trata de un niño de ocho años y cuatro meses de edad, del ámbito rural, que presentaba un cuadro de fiebre de seis días de evolución, acompañado de dolor y distensión abdominal. En la evaluación inicial la exploración fue negativa, a excepción de múltiples erosiones en antebrazo, brazo izquierdo y piernas, así como pústula de aproximadamente $0,5 \mathrm{~cm}$ en cara externa de brazo izquierdo y adenopatía axilar izquierda.

Los datos de laboratorio iniciales incluyeron, leucocitosis 12.400 con $69 \%$ de granulocitos, $8 \%$ de monocitos, $23 \%$ de linfocitos, VSG $63 \mathrm{~mm} / \mathrm{h}$, cultivo de sangre y heces negativos, tuberculina 2UI PPD negativa, orina normal, radiografía de tórax y senos normal, pruebas de función hepática normales.

Mantienen los picos febriles con una frecuencia diaria. Ante la sospecha de fiebre botonosa, se inicia tratamiento con doxiciclina a dosis habitual, que se suspende a los seis días ante la negatividad de la serología de Rickettsia conorii.

El paciente continúa presentando picos febriles, programándose nuevos estudios complementarios, que revelaron un recuento de leucocitos normal, VSG $92 \mathrm{~mm} / \mathrm{h}$, citomorfología normal, PCR $3 \mathrm{mg} / \mathrm{dl}$, pruebas hepáticas normales, aglutinaciones a Salmo nella y Brucella negativas, serología de Epstein Barr, Citomegalovirus, Hepatitis, HIV, Borrelia burgdorfe ri negativas. La ecografía abdominal, revela la presencia de múltiples imágenes hipoecoicas, la mayor de ellas de $6 \mathrm{~mm}$, a nivel de bazo y en el hígado imagen similar única de $5 \mathrm{~mm}$ de diámetro (Fig.1). La TAC abdominal con contraste (Fig.2) corrobora los hallazgos ecográficos y sugiere la posibilidad diagnóstica de microabscesos o Enfermedad por Arañazo de Gato; se solicita serología a Bartonella Henselae, que es positiva, iniciándose tratamiento con eritromicina.

Ante la persistencia de picos febriles y dolor abdominal, se sustituye la eritromicina por rifampicina más gentamicina, constatándose a los tres días de iniciado dicho tratamiento mejoría clínica y desaparición de la fiebre, cuya duración total fue de 28 días.

\section{Caso 2}

Mujer, de trece años, que presenta un cuadro de fiebre de 12 días de evolución acompañado de ade-

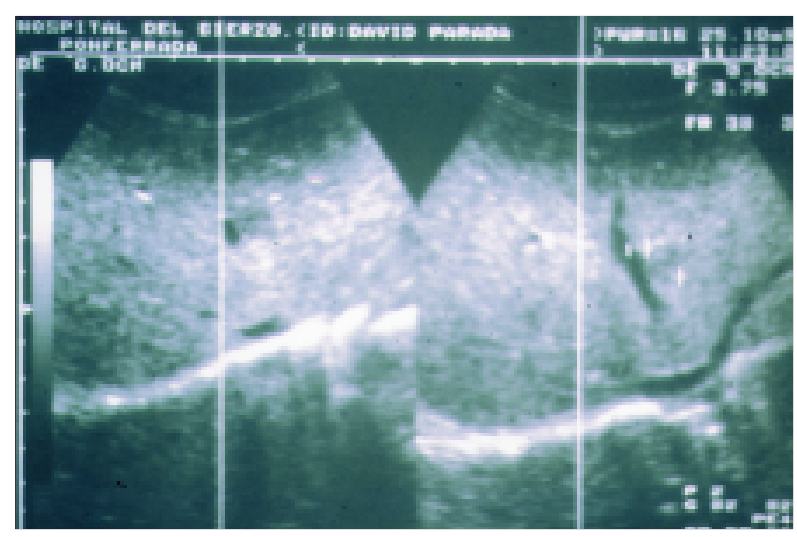

Figura 1

Lesión hepática hipoecoica única de unos $5 \mathrm{~mm}$ de diamétro.

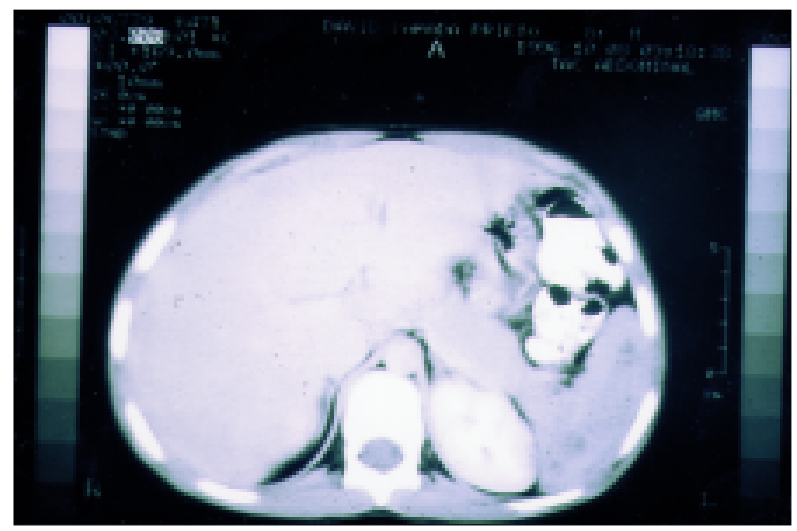

Figura 2

TAC abdominal en la que se aprecian lesiones hipodensas, múltiples, no captantes en bazo, así como hepatomegalia leve.

nopatía axilar izquierda. La exploración inicial fue negativa a excepción de arañazos en mano izquierda. Los datos de laboratorio iniciales incluyeron: leucocitos 4.700 (32\% linfocitos; 9\% monocitos y 51\% granulocitos); VSG 14 mm/h; PCR 2,4 mg/dl; hemocultivo negativo.

Ante la persistencia de la fiebre y la presencia de la adenopatía se sospecha Enfermedad por Arañazo de Gato, se realiza serología a Bartonella henselae y se inicia tratamiento con rifampicina, desapareciendo la fiebre después de 3 días de iniciado el tratamiento. Posteriormente se confirma el diagnóstico al resultar positiva la serología a Bartonella henselae.

\section{DISCUSIÓN}

Tradicionalmente el diagnóstico de Enfermedad por Arañazo de Gato se había basado en la presencia de tres de los siguientes cuatro criterios ${ }^{7}$ :

- Historia de contacto con gato, asociado a lesión de inoculación cutánea o conjuntival.

-Prueba cutánea positiva. 
—Estudios de laboratorio negativos para otras causas de adenopatía.

- Hallazgos anatomopatológicos concordantes en el estudio biópsico de piel o ganglio linfático.

Con respecto a la prueba cutánea, aunque su tasa de positividad es elevada, debe de realizarse con un antígeno no estandarizado y de difícil obtención ${ }^{8}$.

La biopsia ganglionar debería limitarse a aquellos casos en los que el diagnóstico no pudiera ser hecho mediante técnicas no invasivas ya que los hallazgos histopatológicos (hiperplasia linfoide, granulomas con necrosis central a menudo estrellada y conteniendo un número variable de neutrófilos), son sugerentes pero inespecíficos. La presencia de un bacilo pleomórfico y argirófilo mediante la tinción de Warthin-Starry en el interior de las paredes vasculares, macrófagos y áreas de necrosis es demostrativo de la enfermedad ${ }^{9,10}$, pero su positividad es muy baja en estadios iniciales y avanzados.

La existencia de un 10 a un $15 \%$ de formas atípicas, supone una dificultad añadida al diagnóstico requiriendo en la mayoría de las ocasiones, estas formas atípicas, pruebas diagnósticas invasivas: laparotomía diagnóstica, biopsia hepática, etc.

El agente etiológico de la Enfermedad por Arañazo de Gato ha sido controvertido. En los últimos años, Regnery et al demostraron que el $88 \%$ de los enfermos diagnosticados de Enfermedad por Arañazo de Gato presentaban títulos elevados a Bartonella henselae anteriormente denominada Rochalimae henselae. Posteriormente se aisló Bartonella henselae en ganglios linfáticos de enfermos y en el aspirado ganglionar con el que se preparaba el reactivo de las pruebas cutáneas ${ }^{11}$. También se consiguieron aislar secuencias de ARNr de Bartonella henselae en material purulento de ganglios linfáticos de tres pacientes con Enfermedad por Arañazo de Gato ${ }^{12}$. Estos hallazgos junto con las referencias bibliográficas que demuestran la elevación de títulos frente a Bartonella henselae con respecto a los controles en casos de Enfermedad por Arañazo de Gato ${ }^{13}$; sugieren que la Bartonella hense lae sea el agente etiológico de dicha enfermedad.

Múltiples publicaciones apoyan la tesis defendida por Regnery et al y describen técnicas serológicas de detección de Bartonella henselae con sensibilidad y especificidad elevadas ${ }^{14}$, por lo que se han convertido en uno de los principales pilares diagnósticos en la actualidad $^{15,16,17}$.
En los dos casos descritos, que ejemplifican la forma sistémica, y la forma clásica de la enfermedad (linfoadenopatías locorregional subaguda) fue posible el diagnóstico sin la necesidad de realizar pruebas invasivas, ni prueba cutánea. Se utilizaron como criterios diagnósticos la presencia de los tres siguientes:

- Historia de contacto con gato, asociado a lesión de inoculación cutánea o conjuntival.

—Estudios de laboratorio negativos para otras causas de adenopatía.

- Serología positiva a Bartonella henselae o seroconversión.

Este nuevo enfoque diagnóstico posibilita el manejo de la Enfermedad de Arañazo de Gato desde Atención Primaria, evitando derivaciones innecesarias y técnicas invasivas en una enfermedad de curso generalmente benigno.

Con respecto al tratamiento, los pacientes con encefalitis o manifestaciones sistémicas severas, deberían recibir antibioterapia aunque su eficacia no está clara. No existen estudios comparativos randomizados y tampoco se ha descrito ningún fracaso terapeútico, aunque suele utilizarse en estos casos aminoglucósidos, quinolonas, macrólidos y doxiciclina ${ }^{18}$, con una duración variable casi siempre superior a dos semanas. Dado que Bartonella henselae es sensible in vitro a la mayoría de los antibióticos se han utilizado también TMP-SMX, rifampicina ${ }^{19}$, eritromicina, claritromicina y azitromicina. Sin embargo, cada vez son más los partidarios de adoptar una actitud expectante, que debe complementarse con una explicación cuidadosa al enfermo y a su familia de las características de la enfermedad ${ }^{20}$ y con un seguimiento frecuente con una finalidad ansiolítica.

\section{CORRESPONDENCIA:}

M.T. González Martínez

Servicio de Pediatría. Hospital del Bierzo

C/ La Dehesa s/n.

24411 Ponferrada

León

e-mail: teglez@inicia.es

\section{Bibliografía}

1. Margileth AM, Wear DJ, English CK. Systemiccat scratch disease: Report of 23 patients with prolonged or recurrent severe bacterial infection. J Inf Dis 1987; 155: 390-402.

2. Regenery RL, Olson JG, Perkins BA, Bibb W. Serological response to "Rochalimaea henselae" antigen in Suspected catscratch disease. Lancet 1992; 339: 1443-45.
3. Perkins BA, Swaminathan B, Jackson LA, Brenner DJ, Wenger JD, Regnery RL. Case 22 -1992. Pathogenesis of cat scrath disease. N Engl J Med 1992; 327: 1599-600.

4. Anderson B, Kelly C, Threlkel R, Edwards K. Detection of Rochalimaea henselae in cat- scratch disease skin test antigens. J Inf Dis 1993; 168: 1034-6. 
5. Szelc-Kelly CM, Simin Gora L, Pérez-Pérez GI, PerKins BA, Regnery RL , Edwarda KM. Respuestas serológicas a los antígenos de de Bartonella y Afipia en pacientes con enfermedad por arañazo de gato. Pediatrics (ed esp) 1995; Vol 40 (6): 66-72.

6. Nadal D, Zbinden R. Serological response to Bartonella (Rochalimae henselae) may replace traditional diagnostic criteria for cat scratch disease. Eur J Pediatr 1995; 154: 906-8.

7. Carithers H A. Cat scrath disease: an overview based on a study of 1200 patients. Am J Dis Child 1985; 139: 1124-33.

8. Kalter SS, Rodríguez AR, Herberling RL. Cat scrath disease skin-test antigen preparation. Lancet 1977; 2: 606-7.

9. Wear DJ, Margileth AM, Hadfield TL, Fishcer G, Schagel C, King F. Cat scratch disease: a bacterial infection. Science 1983; 221: 1403-4.

10. Margileth AM, Wear DJ, Hadfield TL, English CK. Cat scrath disease: bacteria in skin at the primary inoculation site. JAMA 1984; 252: 928-31.

11. Anderson B, Kelly C. Threlkel R, Edwards K. Detection of Rochalimaea Henselae in Cat-Scratch Disease Skin Test Antigens. J Inf Dis 1993; 168: 1034-6.

12. Bergmans AMC, Groothedde JW, Schellkens JFP,Van Embden JDA, Ossewaarde JM, Schouls LM. Etiology of Cat Scratch Disease: Comparison of Polymerasa Chain Reaction Detection of Bartonella (Formerly Rochalimaea) and Afipia felis DNA with Serology and Skin tests. J Inf Dis 1995; 171: 916-23.

13. Raoult D, Tissot Dupont H, Enea-Mutillod M. Positive predictuve value of Rochalimaea henselae antibodies in the diagnosis of cat scratch disease. Clin Infect Dis 1994; 19: 355

14. Zangwill KM, Hamilton DH, Perkins BA, Regnery RL, Plikaytis BD, Hadler JL, et al. Cat scrath disease in Connesticut. Epidemiology, risk factors, and evaluation of a new diagnostic test. N Eng J Med 1993; 329 No.1: 8-13.

15. Numazaki K, Chiba S, Ueno H. Infected dogs and cats. N Engl J Med 1999, 340: 1842.

16. Riviello JJ. Case 1-1998 en Case Records of The Massachussets General Hospital 98. N Engl J Med 1998; 338: 112-9.

17. Harrison TG, Doshi N. Serological evidence of Bartonella sp. Infection in the UK. Epidemiol Infect 1999; 123 (2): 233-40.

18. Stuart Tompkins L. Bartonella infections, including cat-scratch disease. En: Harrison's Principles of Internal Medicine. McGraw-Hill. 14ª ed. (soporte informático) 1998; 165.

19. Margileth Andrew M. Antibiotic therapy for cat-scratch disease: clinical study of therapeutic outcome in 268 patients and a review of the literature. Pediatr Infect Dis J, 1992; 11: 474-8.

20. Giladi M, Avidor B. Cat scrath disease. N Engl J Med 1999; 340: 108 